\title{
Acoustic structure of songs in island populations of the Japanese bush warbler, Cettia diphone, in relation to sexual selection
}

\author{
Shoji Hamao
}

Received: 12 August 2011/Accepted: 22 July 2012/Published online: 10 August 2012

(C) Japan Ethological Society and Springer 2012

\begin{abstract}
Bird songs in island populations have often been reported to be simplified, in that island birds have a smaller number of song types and song-element types compared to mainland birds. However, there is less information on the characteristics of acoustic structure in island songs. I investigated song structure of one mainland and three island populations of Japanese bush warblers, Cettia diphone, and found that island songs had an acoustically simple structure. The frequency-modulated (FM) portions of the songs were shorter and had fewer frequency inflections in the insular populations than in the mainland population, while the number of FM notes, the frequency range of these notes, and the song repertoire sizes of males did not differ between the islands and the mainland. I also investigated whether the song complexity is related to sexual selection pressure using the degree of sexual size dimorphism as a proxy for the latter. The degree of dimorphism in body mass was larger on the mainland. Thus, weakened sexual selection on islands is a possible factor in the formation of simple songs. Further studies related to malemale competition and female choice on islands are required.
\end{abstract}

Keywords Cettia diphone - Island population .

Japanese bush warbler $\cdot$ Sexual selection · Song repertoire . Song structure

\section{Introduction}

Bird song is an acoustic signal that has functions in territorial advertisement and mate attraction (Catchpole and

S. Hamao $(\bowtie)$

Department of Zoology, National Museum of Nature and Science, 4-1-1 Amakubo, Tsukuba, Ibaraki 305-0005, Japan e-mail: hamao@kahaku.go.jp
Slater 1995). Thus, songs have evolved under the influences of various ecological and social factors (Kroodsma and Miller 1996). Environments on islands differ from those on the mainland, and the songs of island birds are predicted to have unique characteristics. Bird songs in island populations have often been reported to be simplified, in that island birds have a smaller number of song types (Milder and Schreiber 1989; Naugler and Smith 1991; Schöttler 1995; Baker 1996) and song-element types (Baptista and Johnson 1982; Kroodsma 1985; Baker and Jenkins 1987; Schöttler 1995; Baker 1996) compared to mainland birds. One factor that causes the smaller repertoires on islands is the founder effect (Baker and Jenkins 1987; Naugler and Smith 1991; Baker 1996; Baker et al. 2006); the few colonists of an island carry a small fraction of the mainland songs and song elements, and island songs are formed from these materials. Sound transmission properties are another possible factor (Jenkins and Baker 1984; Kroodsma 1985). Habitat structure influences sound transmission properties and, consequently, long-distance communication signals such as songs (Morton 1975; Richard and Wiley 1980). Therefore, in cases where habitat structure differs between an island and the mainland, songs may adaptively change on the island.

Compared to findings on repertoire size, there is less information on the characteristics of acoustic structure in island songs. Some studies have found that song structure on islands is also simplified. For example, smaller numbers of song elements in a song have been reported in insular birds (Jenkins and Baker 1984; Kroodsma 1985). However, the simple structure is often estimated by qualitatively visual inspection of the sound spectrograms of songs (Milder and Schreiber 1989; Catchpole and Komdeur 1993; Schöttler 1995). Therefore, it remains uncertain whether the acoustic structure of songs is simpler on islands and 
which factors affect the song structure. It is important to quantitatively analyze the characteristics of the acoustic structure of island songs to better understand geographical variations in bird song.

Japanese bush warblers, Cettia diphone, are distributed throughout the main islands of Japan and on small peripheral islands (Ornithological Society of Japan 2000). In a previous study, a colleague and I compared the songs of an island population [ $C$. $d$. diphone on Haha-jima of the Ogasawara Islands (Bonin Islands)] and a mainland population ( $C$. $d$. cantans in Honshu) and found that the island songs were acoustically simpler; each song contained fewer notes and frequency inflections and a smaller frequency range (Hamao and Ueda 2000). Social factors are thought to have played an important role in producing these differences. Males on the mainland are highly polygynous and do not maintain pair-bonds or undertake parental care (Hamao 1992), whereas males on the island guard their mates and feed their nestlings (Hamao and Ueda 1999). Therefore, the pressure of sexual selection was inferred to be weaker on the island. Since strong sexual selection shapes complex songs (Searcy and Andersson 1986), weaker selection on the island would yield simpler songs (Hamao and Ueda 2000). This previous study, however, investigated the songs of only a single insular population. Moreover, the mainland and insular populations had clearly distinctive breeding systems. To clarify the general trends in the island songs of Japanese bush warblers, further research on other island populations is required. Also, to determine whether sexual selection affects island songs, we must investigate the relationship between song characteristics and selection pressures.

In the present study, I used one mainland and three island populations to examine whether insular Japanese bush warblers generally have acoustically simple songs. I also examined whether the characteristics of island songs can be explained by differences in sexual selection pressure. I used the degree of sexual size dimorphism to indicate selection pressure because this species shows distinct sexual size dimorphism (Hamao 1992; Hamao et al. 2006). I predicted that song structure would be simpler on islands than on the mainland and that the complexity of songs would be positively correlated with the degree of sexual size dimorphism.

\section{Materials and methods}

Study sites and populations

I conducted the study on three islands (Nii-jima, Miyakejima, and Kikai-jima) and at a mainland study site
(Ranzan). None of the study sites were included in the previous study (Hamao and Ueda 2000).

Nii-jima $\left(34^{\circ} 22^{\prime} \mathrm{N}, 139^{\circ} 16^{\prime} \mathrm{E}\right.$; ca. $\left.23 \mathrm{~km}^{2}\right)$ and Miyakejima $\left(34^{\circ} 05^{\prime} \mathrm{N}, 139^{\circ} 31^{\prime} \mathrm{E}\right.$; ca. $\left.55 \mathrm{~km}^{2}\right)$ are located 155 and $180 \mathrm{~km}$ south of Tokyo, respectively. These islands belong to the Izu Islands group. Evergreen forest is the dominant vegetation. Thickets of Pleioblastus chino bamboo are common around cultivated fields, providing nesting habitat for the warblers. Kikai-jima $\left(28^{\circ} 18^{\prime} \mathrm{N}, 129^{\circ} 56^{\prime} \mathrm{E}\right.$; ca. $57 \mathrm{~km}^{2}$ ) is located $295 \mathrm{~km}$ south from the nearest main island, Kyushu. The dominant vegetation is evergreen forest. Introduced Napier grasses, Pennisetum purpureum, form thickets around cultivated fields, providing nesting habitat for the warblers. The study site on the mainland was at Ranzan $\left(36^{\circ} 01-06^{\prime} \mathrm{N}, 139^{\circ} 18-20^{\prime} \mathrm{E}\right)$ in central Honshu, the largest island of Japan $\left(227,970 \mathrm{~km}^{2}\right)$. Deciduous forests and bamboo thickets dominate, and the warblers nest in the thickets.

\section{Field work}

I collected song recordings and body measurements during the breeding seasons (April-July) of 2002-2008. Songs from a singing male were recorded for at least $5 \mathrm{~min}$, which was sufficient to obtain all song types of the male because the repertoire size of the warblers was fairly small (two to six song types), and because males sang very frequently at short intervals. I used a Sony TCD-D7 DAT-recorder (Nii-jima and Ranzan) or a Sony PCM-D1 digital recorder (Miyakejima and Kikai-jima) equipped with a Sony ECM-G3M directional microphone. I obtained song recordings from 20, 24, 43, and 38 males on Nii-jima, Miyake-jima, Kikai-jima, and Ranzan, respectively. Although I did not individually mark the males, I avoided duplicate sampling of the same males by walking along roads and recording new males when I encountered them, and using each route only once. Moreover, I recorded songs from each study site within a single breeding season (Nii-jima: 2002; Miyake-jima: 2006; Kikai-jima: 2008; Ranzan: 2003), because a male might change its territory from one breeding season to the next.

I captured the warblers using mist-nets and used calipers to measure the lengths of the wing (wing unflattened), tail, tarsus, and bill (distance from the tip of the bill to the nostril) to the nearest $0.01 \mathrm{~mm}$. A digital balance was used to measure body mass to the nearest $0.1 \mathrm{~g}$. Sex was identified by differences in body size; males are much larger than females (Yamashina 1941; Hamao 1992). I measured 8 males and 2 females on Nii-jima, 11 males and 13 females on Miyake-jima, 37 males and 21 females on Kikai-jima, and 16 males and 13 females at Ranzan, but I failed to obtain tail length from 2 males (both at Ranzan) and body mass from 2 birds ( 1 male on Nii-jima and 1 female on Miyake-jima). 
Analyses

All recorded sounds were digitized (16-bit resolution and 32-kHz sample rate) and analyzed using a computer-based analysis system (Avisoft-SASLab Pro, v.5.1). Sounds were displayed as sound spectrograms. Fast Fourier transform (FFT) lengths of 256 and 1,024 were used to produce plots for temporal and frequency measurement, respectively. The songs of Japanese bush warblers consist of an initial constant frequency (CF) and subsequent frequency modulation (FM; Hamao 1993; Momose 1999; Hamao and Ueda 2000; Fig. 1). The complexity of songs was assessed using four measurements of the FM part of the song: the number of notes, the number of frequency inflections [i.e., the number of changes in the sign of the derivative (slope) of the frequency on the sound spectrogram], the length (duration), and the frequency range (i.e., the difference between the highest and the lowest frequencies; Fig. 1). A note is a discrete song element (Catchpole 1980; Baker 1996) and was defined as any continuous trace on a spectrogram. In successive renditions of the same song type by the same male, the frequency of the CF part varies each time, but the FM part is always repeated with high stereotypy (Hamao 1993; Momose 1999). Therefore, I collected song measurements of the FM part from one song in each song type of a male.

I recorded the number of song types of each male. The warblers have two basic song types: a type-H song and a type-L song (Hamao 1993; Momose 1999). The CF part of the type-L song consists of several short whistles, whereas that of the type-H song is one continuous whistle. The FM part of the type-H song generally contains more notes than that of the type-L song. Males use type-H songs in territory patrolling and type-L songs towards intruders (Momose 2000). Because the two song types have clear differences not only in acoustic structure but also in function, I recorded the number of song types that could be assigned to type- $\mathrm{H}$ and type- $\mathrm{L}$.

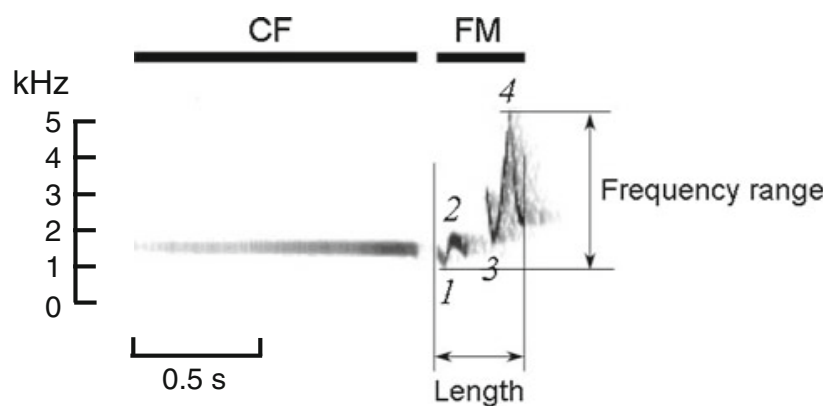

Fig. 1 Spectrogram of a Japanese bush warbler Cettia diphone song showing the parameters analyzed. A type-H song that contains two notes and four inflections in its frequency modulated (FM) part is shown
To compare song structure among the four study sites, I used generalized linear mixed models (GLMMs). The number of FM notes and frequency inflections of these notes were analyzed using a GLMM with a log-link and Poisson error distribution. The length and frequency range in the FM part were analyzed using a GLMM with identitylink and Gaussian error distribution. I included site as a fixed factor and male identity as a random factor. To compare the number of song types of males, I used generalized linear models (GLMs) with a log-link and Poisson error distribution. For these analyses, I made separate models of type- $\mathrm{H}$ and type- $\mathrm{L}$ songs. To test for significance, I compared the song variables between two study sites (all combinations among the four sites) using likelihood ratio tests with sequential Bonferroni correction (Rice 1989).

I used the degree of sexual size dimorphism to estimate the pressure of sexual selection. I used differences between males and females in body measurement variables (lengths of the wing, tail, tarsus, and bill, and body mass) as indicators of the degree of sexual size dimorphism. To examine differences in the degree of dimorphism between sites, I used a GLM with identity-link and Gaussian error distribution. The explanatory variables were sex, site, and their interaction. I determined the significance of differences in the degree of sexual size dimorphism by testing the significance of the interaction, following Price (1984). When testing the significance of the interaction between two study sites, I used likelihood ratio tests with sequential Bonferroni correction (Rice 1989).

Here, I report $p$ values that have been corrected by the Bonferroni methods. In all analyses, the significance levels were set at 0.05 , and analyses were conducted using $R$ software (v.2.12.1; R Development Core Team 2010).

\section{Results}

The FM portions of the songs were longer in the mainland population than in the three island populations, both for type-H and type-L songs (Fig. 2a). The FM length of type$\mathrm{H}$ songs was longer on Nii-jima than on Miyake-jima and Kikai-jima. The number of inflections in FM notes was larger on the mainland than on the three islands, except for a non-significant trend in type- $\mathrm{H}$ songs between Ranzan and Nii-jima (Fig. 2b). On the other hand, the number of FM notes did not show clear differences between the islands and the mainland, although there were fewer FM notes in type-L songs on Miyake-jima and Kikai-jima than at Ranzan (Fig. 2c). The frequency range in the FM portions did not differ among the sites (all $p>0.9$ for type- $\mathrm{H}$ songs, all $p>0.15$ for type-L songs; Fig. 2d). Also, no difference was found in the number of song types of males 


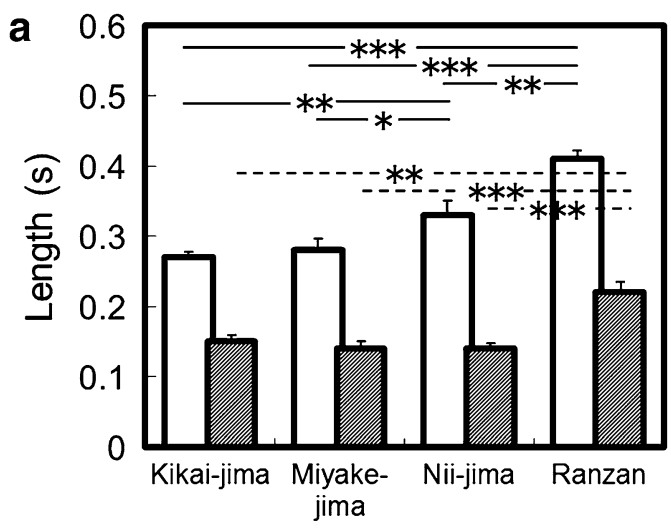

b
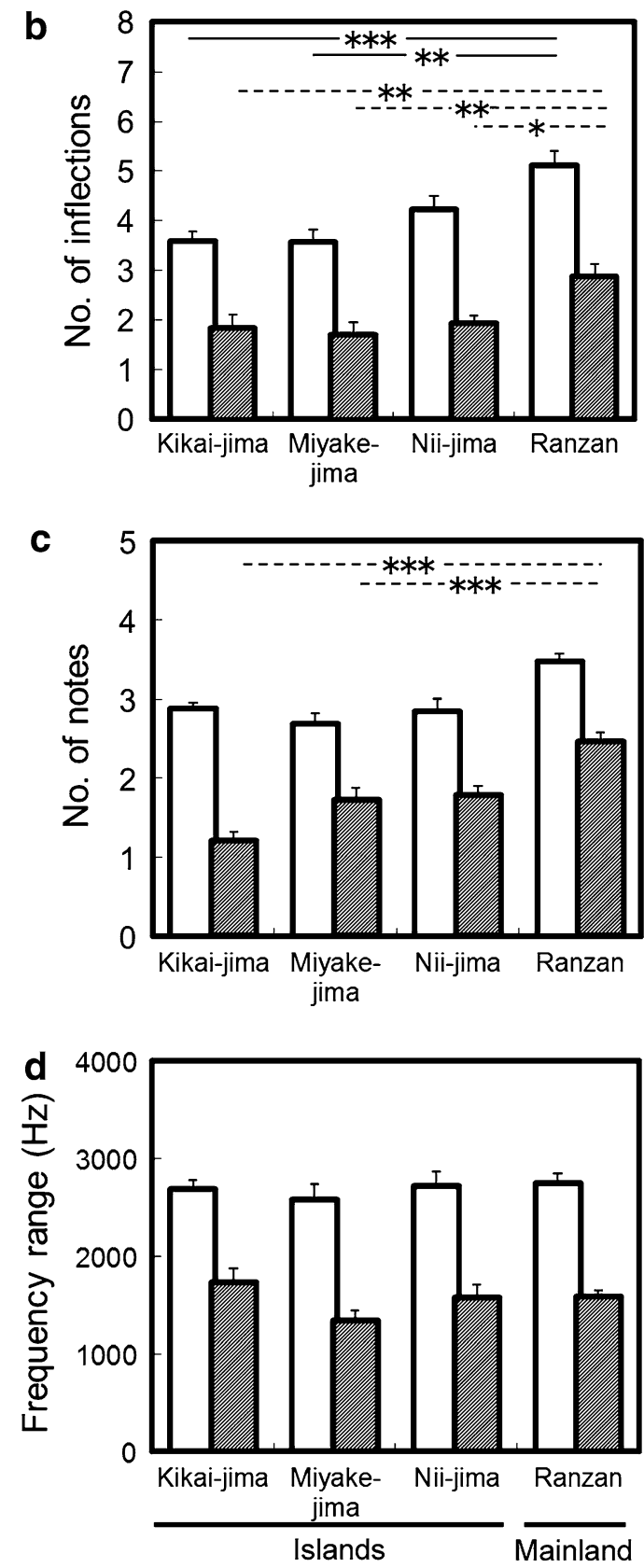

4 Fig. 2 Differences in the song structure of Japanese bush warblers among one mainland and three island populations: length (a), number of inflections (b), number of notes (c), and frequency range (d) of the FM part of the songs. Means $+1 \mathrm{SE}$ are shown. White bars type- $\mathrm{H}$ songs, black bars type-L songs. Horizontal solid and dotted lines indicate significant differences in type- $\mathrm{H}$ and $-\mathrm{L}$ songs, respectively. $p$ values $(* * * p<0.001, * * p<0.01, * p<0.05)$ have been adjusted by Bonferroni correction

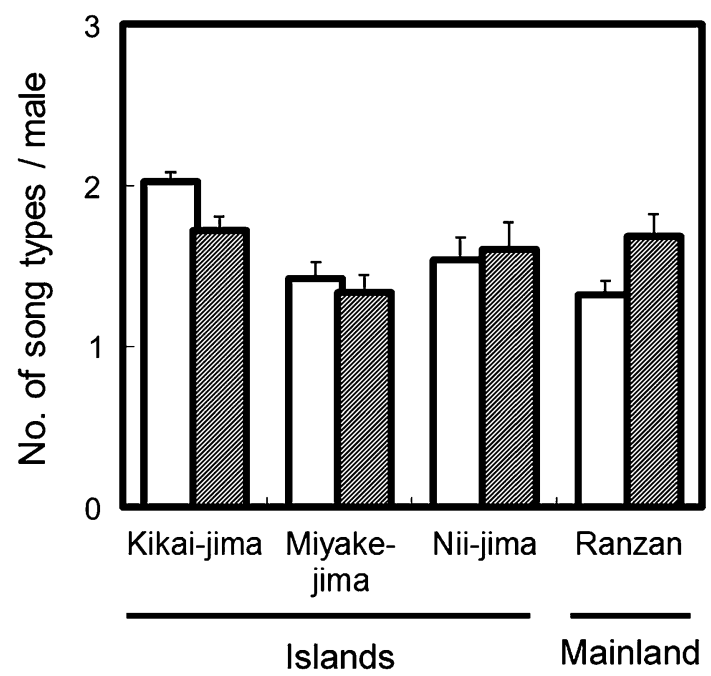

Fig. 3 Differences in the number of song types of Japanese bush warblers among one mainland and three island populations. Mean$\mathrm{s}+1 \mathrm{SE}$ are shown. White bars type-H songs, black bars type- $\mathrm{L}$ songs

(all $p>0.35$ for type-H songs, all $p>0.8$ for type- $\mathrm{L}$ songs) with the exception of a marginal trend of the repertoire of type-H songs being larger on Kikai-jima than at Ranzan $\left(\chi_{1}^{2}=6.07, p=0.08\right.$; Fig. 3).

Wing, tail, tarsus, and bill lengths were larger in males than in females, although the difference in bill length was small (Fig. 4a-d). In these body measurements, the male to female ratios (male/female) did not differ among sites; in the GLM analysis, the interaction between sex and site was not significant (wing: all $p>0.9$; tail: all $p>0.5$; tarsus: all $p>0.24$; bill: all $p>0.8$ ). The ratio of male to female body weight (male/female) was highest at Ranzan and lowest on Nii-jima (Fig. 4e). The GLM analysis showed higher dimorphism at Ranzan and on Miyake-jima; interactions between sex and site were significant between Ranzan and Nii-jima, Ranzan and Kikai-jima, Miyake-jima and Niijima, and Miyake-jima and Kikai-jima (all $p<0.05$ ).

\section{Discussion}

The FM portions of the songs were shorter and had fewer frequency inflections in the three insular populations than 
Fig. 4 Differences in the degree of sexual size dimorphism of Japanese bush warblers among one mainland and three island populations: ratio of male to female wing (a), tail (b), tarsus (c), and bill length (d), and body mass (e). Horizontal lines indicate significant differences in the interaction of sex and site with body mass. $p$ values $(* p<0.05)$ have been adjusted by Bonferroni correction
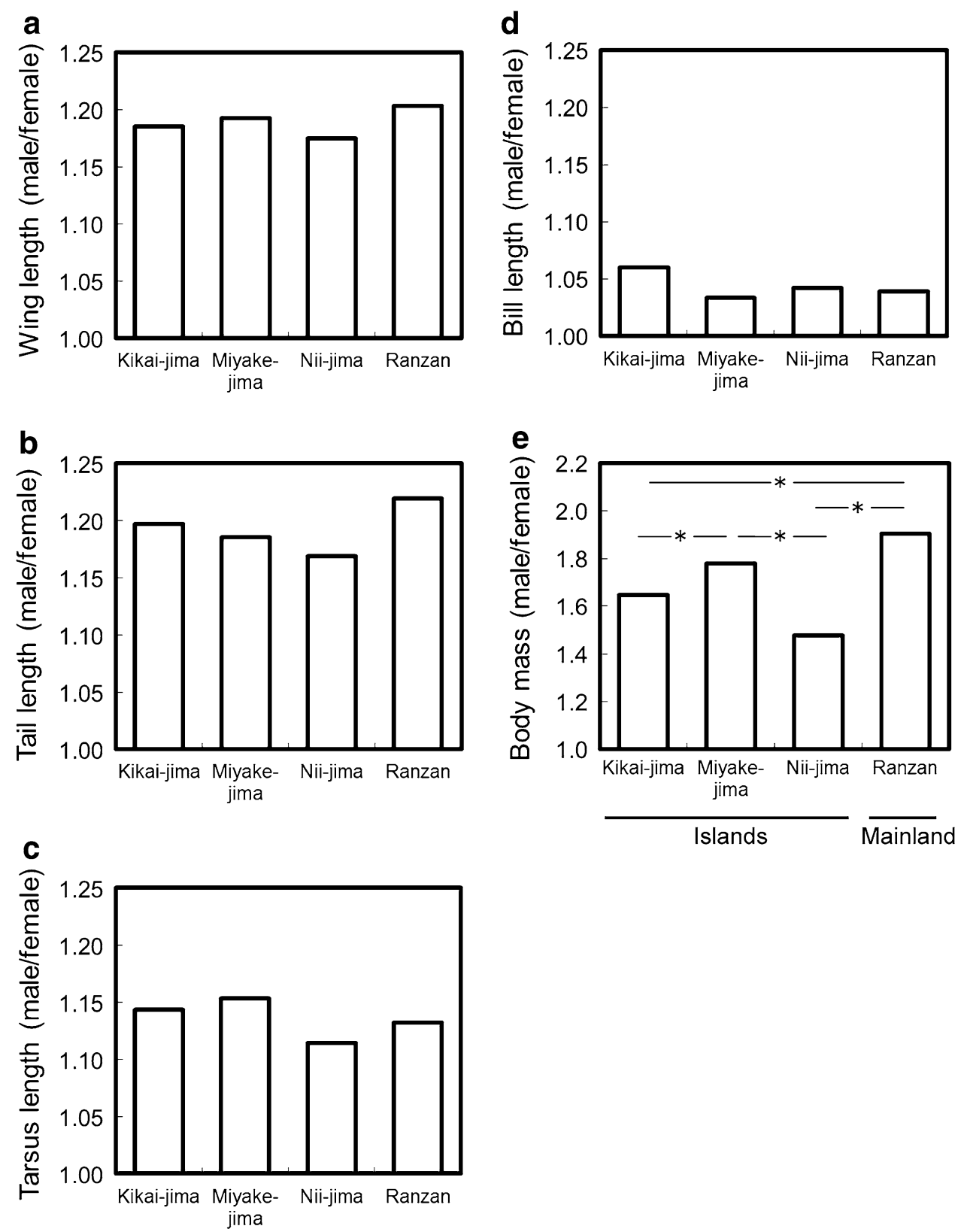

in the mainland population, while the number of FM notes, the frequency range of these notes, and the song repertoire sizes of males did not show clear differences between the islands and the mainland (Figs. 2, 3). The results demonstrate that the songs on the islands had a simpler acoustic structure.

Since strong sexual selection shapes complex songs (Searcy and Andersson 1986), I predicted that the complexity of songs would be positively correlated with the degree of sexual size dimorphism. My results show that the degree of dimorphism was large on the mainland, but the trend was only found during the analysis of body mass and not wing, tail, tarsus, and bill lengths (Fig. 4). Since, in each habitat, the morphology of each body part is adaptively shaped through ecology (e.g., migration, foraging behaviors; Winkler and Leisler 1985; Lockwood et al. 1998), the lengths of individual body parts may not indicate the degree of sexual size dimorphism. For example, small differences in the male/female ratio for bill length among sites may have occurred because both sexes exploit similarly sized food in their habitat. Therefore, body mass is likely the best indicator of sexual size dimorphism and a proxy for sexual selection pressure. Thus, the simpler structure of songs on the islands may be related to weaker sexual selection.

On the mainland, male warblers are highly polygynous as a result of the frequent mate-switching of females due to nest predation (Hamao 1992). Nest predation by snakes and 
predatory mammals is very frequent in Honshu $(73 \%$ of nests: Hamao 1992; $81 \%$ : Uchida 2011). In contrast, few predators live on the islands; no snakes inhabit Miyakejima (Hasegawa 2003; Fujita et al. 2011) or Kikai-jima (Sakagami et al. 2011), and no mammalian carnivores are distributed in the study islands except for recently introduced Japanese weasels, Mustela itatsi, on Miyake-jima (in the early 1980s: Hasegawa 1994) and Kikai-jima (in 1942: Mitsui 1965; Uchida 1969). Nesting failure on the islands is unlikely to be frequent, and males may not be highly polygynous. Moreover, territorial males are frequently replaced on the mainland (Hamao 1992), whereas males can maintain their territories for longer periods on the islands (Hamao 2010). Furthermore, males on the three islands did not actively sing in the middle of the day, whereas males on the mainland actively sang throughout the day (personal observation). This indirect evidence implies that male-male competition and mate choice by females are less intense on the islands. Contrary to the previously studied population $(C . d$. diphone on Hahajima), in which males undertook parental care and mate guarding (Hamao and Ueda 1999), the warblers on the three islands in the present study do not have markedly different breeding ecology from that of mainland warblers. However, weakened sexual selection pressure on the islands appears to result in simplified songs. Further study is required to elucidate the degree of sexual selection pressure at each site (e.g., the skew of male mating success) and the relationship between song structure and sexual selection on the islands.

Another possible factor for the simplified songs may be the sound transmission properties on the islands (Jenkins and Baker 1984; Kroodsma 1985). Habitat structure influences sound transmission properties and, consequently, bird vocalizations. Birds inhabiting forests use pure tonelike, low-frequency sounds that attenuate less in their habitats (Morton 1975; Richard and Wiley 1980). Therefore, as was argued by Jenkins and Baker (1984), it is plausible that the decrease in note types and the number of notes in the songs of chaffinches, Fringilla coelebs, is related to the sound transmission properties of dense pine forests. Also, in Japanese bush warblers, it cannot be ruled out that the vegetation on the islands affects sound transmission and, consequently, the structure of songs. However, the nesting habitat of the warblers was composed of grassland on Kikai-jima and bamboo thickets at the other study sites. The bamboo thickets have existed for a long period of time on both the mainland and the islands, although Napier grasses were introduced on Kikai-jima by artificial cultivation. It is unlikely that the sound transmission properties on the islands always engender a simple song structure. Also, there is no evidence that complex songs are appropriate for the sound transmission properties on the mainland. Therefore, it is not likely that sound transmission properties were responsible for the simplified songs found in the insular populations of Japanese bush warblers.

Simplified songs on islands are often interpreted as a result of the founder effect. The founder effect does result in limited repertoires of songs and song elements on islands at population levels (Baker and Jenkins 1987; Tracy and Baker 1999). However, it cannot explain the acoustically simple trends of songs on islands. It is unlikely that, on all the islands I studied, the colonists by chance brought to the islands only simple songs (or song elements) from the mainland. Therefore, the founder effect could not have shaped the acoustic structure of the warblers' songs.

No significant difference was found in the number of song types of males between the islands and the mainland, whereas previous research showed a larger song repertoire on an island (Hamao and Ueda 2000). Under weak selection pressure, when young birds err in song learning, the changed songs will not be selected out and will remain in the population (Martens 1996). Such cultural mutations will accumulate in the population over a long time (Jenkins 1977; Lynch 1996). In this context, one might conjecture that song repertoires should be larger on the islands in the present study. However, the population previously studied by a colleague and myself ( $C$. $d$. diphone) had diverged a very long time prior to the divergence of other populations of this species in Japan (Kajita 2002; I. Nishiumi, personal communication). The accumulation of cultural mutations may require a long period. The warblers on Nii-jima, Miyake-jima, and Honshu (Ranzan) belong to C. d. cantans, while the birds on Kikai-jima belong to $C$. $d$. restricta, which differs somewhat from $C$. $d$. cantans in its mitochondrial DNA (Kajita 2002; I. Nishiumi, personal communication). The marginal trend showing a larger repertoire on Kikai-jima might indicate that long periods on isolated islands produce variable songs through cultural mutations.

In summary, the present study of three island populations and one mainland population of Japanese bush warblers shows that island songs have a simpler acoustic structure. The degree of sexual size dimorphism provides partial support for the idea that weakened sexual selection on islands is a factor in the formation of simple songs. Long periods might be necessary to accumulate learning errors and to increase repertoire size. Further ecological studies related to male-male competition and female choice on islands are required.

Acknowledgments I am grateful to H. Uchida, S. Isobe, T. Hamao, and the staff of the Miyake-jima Nature Center Akakokko Station, especially Y. Yamamoto, H. Shinoki, and I. Ezaki, for their valuable information and support of my field work. I am indebted to the Miyake Village Office for permitting the field study and providing lodging, and to the Kikai Town Office for assistance during the field 
work. Thanks are also due to three anonymous reviewers for their comments and suggestions, and to I. Nishiumi for information regarding his DNA analyses. This study was supported by a Grant-inAid for Scientific Research (C) (No. 17570028) from the Japan Society for the Promotion of Science, and by the research project of the National Museum of Nature and Science, "Historical development and origin of biodiversity under global environment dynamics".

\section{References}

Baker MC (1996) Depauperate meme pool of vocal signals in an island population of singing honeyeaters. Anim Behav 51:853-858

Baker AJ, Jenkins PF (1987) Founder effect and cultural evolution of songs in an isolated population of chaffinches, Fringilla coelebs, in the Chatham Islands. Anim Behav 35:1793-1803

Baker MC, Baker MSA, Tilghman LM (2006) Differing effects of isolation on evolution of bird songs: examples from an islandmainland comparison of three species. Biol J Linn Soc 89:331-342

Baptista LF, Johnson RB (1982) Song variation in insular and mainland California brown creepers (Certhia familiaris). J Ornithol 123:131-144

Catchpole CK (1980) Sexual selection and the evolution of complex songs among European warblers of the genus Acrocephalus. Behaviour 74:149-165

Catchpole CK, Komdeur J (1993) The song of the Seychelles warbler Acrocephalus sechellensis, an island endemic. Ibis 135:190-195

Catchpole CK, Slater PJB (1995) Bird song: biological themes and variations. Cambridge University Press, Cambridge

Fujita K, Fujita G, Hasegawa M, Higuchi H (2011) Inference of population sizes and factors affecting distributional stability of three subspecies of varied tits among the Izu Islands. Bird Research 7:A13-A31

Hamao S (1992) Lack of pair-bond: a polygynous mating system of the Japanese bush warbler Cettia diphone. Jpn J Ornithol 40:51-65

Hamao S (1993) Individual identification of male Japanese bush warbler Cettia diphone by song. Jpn J Ornithol 41:1-7

Hamao S (2010) Territoriality of the island population of the Japanese bush warbler Cettia diphone restricta, using radio-telemetry. Rept Inst Nat Stu 41:35-47

Hamao S, Ueda K (1999) Reduced territory size of an island subspecies of the bush warbler Cettia diphone. Jpn J Ornithol 47:57-60

Hamao S, Ueda K (2000) Simplified song in an island population of the bush warbler Cettia diphone. J Ethol 18:53-57

Hamao S, Veluz MJS, Nishiumi I (2006) Species recognition by song between the Luzon bush warbler, Cettia seebohmi, and the Japanese bush warbler, $C$. diphone. Mem Natl Sci Mus Tokyo 44:21-29

Hasegawa M (1994) Insular radiation of life history in the lizard Eumeces okadae on the Izu Islands. Copeia 1994:732-747

Hasegawa M (2003) Ecological diversification of insular terrestrial reptiles: a review of the studies on the lizard and snakes of the Izu Islands. Glob Environ Res 7:59-67

Jenkins PF (1977) Cultural transmission of song patterns and dialect development in a free-living bird population. Anim Behav 25:50-78

Jenkins PF, Baker AJ (1984) Mechanisms of song differentiation in introduced populations of chaffinches Fringilla coelebs in New Zealand. Ibis 126:510-524

Kajita M (2002) Intra-specific phylogeography in Cettia diphone. Iden 56:42-46
Kroodsma DE (1985) Geographic variation in songs of the Bewick's wren: a search for correlations with avifaunal complexity. Behav Ecol Sociobiol 16:143-150

Kroodsma DE, Miller EH (eds) (1996) Ecology and evolution of acoustic communication in birds. Cornell University Press, Ithaca

Lockwood R, Swaddle JP, Rayner JMV (1998) Avian wingtip shape reconsidered: wingtip shape indices and morphological adaptations to migration. J Avian Biol 29:273-292

Lynch A (1996) The population memetics of birdsong. In: Kroodsma DE, Miller EH (eds) Ecology and evolution of acoustic communication in birds. Cornell University Press, Ithaca, pp 181-197

Martens J (1996) Vocalizations and speciation of Palearctic birds. In: Kroodsma DE, Miller EH (eds) Ecology and evolution of acoustic communication in Birds. Cornell University Press, Ithaca, pp 221-240

Milder SL, Schreiber RW (1989) The vocalizations of the Christmas Island warbler Acrocephalus aequinoctialis, an island endemic. Ibis 131:99-111

Mitsui Y (1965) Kikai-jima Island in old days. Sanko-insatsu, Tokyo

Momose H (1999) Structure of territorial songs in the Japanese bush warbler (Cettia diphone). Mem Fac Sci Kyoto Univ (Ser Biol) 16:55-65

Momose H (2000) Neighbour-stranger recognition based on song in the Japanese bush warbler (Cettia diphone). Mem Fac Sci Kyoto Univ (Ser Biol) 17:25-32

Morton ES (1975) Ecological sources of selection on avian sounds. Am Nat 109:17-34

Naugler CT, Smith PC (1991) Song similarity in an isolated population of fox sparrows (Passerella iliaca). Condor 93:1001-1003

Ornithological Society of Japan (2000) Check-list of Japanese birds, 6th (rev) edn. Ornithological Society of Japan, Obihiro

Price TD (1984) The evolution of sexual size dimorphism in Darwin's finches. Am Nat 123:500-518

R Development Core Team (2010) R: a language and environment for statistical computing. R Foundation for Statistical Computing, Vienna. http://www.R-project.org

Rice WR (1989) Analyzing tables of statistical tests. Evolution 43:223-225

Richard DG, Wiley RH (1980) Reverberations and amplitude fluctuations in the propagation of sound in a forest: implications for animal communication. Am Nat 115:381-399

Sakagami M, Hamao S, Mori Y (2011) Predation of bird nests on Kikai Island, in the Amami Island group: differences in predation rates among nesting habitats and the identity of predators. Jpn J Ornithol 60:88-95

Schöttler B (1995) Songs of blue tits Parus caeruleus palmensis from La Palma (Canary Islands): a test of hypotheses. Bioacoustics 6:135-152

Searcy WA, Andersson M (1986) Sexual selection and the evolution of song. Annu Rev Ecol Syst 17:507-533

Tracy TT, Baker MC (1999) Geographic variation in syllables of house finch songs. Auk 116:666-676

Uchida TA (1969) Rat-control procedures on the Pacific islands, with special reference to the efficiency of biological control agents. J Fac Agric Kyushu Univ 15:355-385

Uchida H (2011) Breeding biology of the little cuckoo Cuculus poliocephalus: a brood parasite specialized in one host species, the Japanese bush warbler Cettia diphone, in Honshu, Japan. Jpn J Ornithol 60:78-87

Winkler H, Leisler B (1985) Morphological aspects of habitat selection in birds. In: Cody ML (ed) Habitat selection in birds. Academic, New York, pp 435-444

Yamashina Y (1941) A natural history of Japanese birds. Iwanamishoten, Tokyo 